\title{
Antimicrobial Potential: Herbal Cream of Salsola Baryosma
}

\section{Roots}

Khan $\mathrm{DH}^{1}$, Ali MY1,2*, Rasool $\mathrm{S}^{1}$, Ahmed $\mathrm{S}^{3}$, Raza SM ${ }^{1}$, Abbas G ${ }^{1}$

${ }^{1}$ Faculty of Pharmaceutical Sciences, Govt. College University Faisalabad, Pakistan

${ }^{2}$ Department of Pharmaceutical Technology and Biopharmacy, University of Marburg,

Germany

32Department of Pharmacy, The Islamia University of Bahawalpur, Pakistan

\section{Research Article}

Volume 1 Issue 5

Received Date: August 08, 2017

Published Date: August 23, 2017

*Correspondence author: Muhammad Yasir Ali, Faculty of Pharmaceutical Sciences, Govt. College University Faisalabad,

Pakistan, E-mail: m.yasirali14@gmail.com

\section{Abstract}

Salsola baryosma, native to Punjab, Baluchistan, Sindh areas of Pakistan, has folk use of topical anti microbial effects in crude form in Cholistan desert, Pakistan. In present study this activity was used to prepare creams. The plant roots were shade dried and crushed and petroleum ether, chloroform and ethanol extracts were prepared from successive extraction and different creams were prepared. The stable formulations were selected on the behalf of phase change were selected after one week and reformulated and subjected to 28 days stability studies in stability chambers. Stability study, centrifugation, physical testing, irritancy testing and $\mathrm{pH}$ were performed at different intervals from 0 hour to 28 days. The antimicrobial activity of extracts, formulations and Streptomycin as standard was evaluated against E.coli, S.aureus, P.multicoda and B.subtillus. The ethanolic extract and cream showed greater antimicrobial activity as compared to other extracts and formulations. The results were analyzed by applying two way ANOVA. The ethanolic extract and cream showed greatest antimicrobial activity as compared to other extracts and creams as compared to other extracts and formulations.

Keywords: Salsola baryosma; Extraction; Stability studies; Antimicrobial activity

\section{Introduction}

Plants are natural sources and are used for different treatments. In herbal medicines, medicinal plants are the major source and most of new drugs are made from plants or from plant precursors so systemic evaluation of plants is required [1,2]. Salsola baryosma Linn (syn. S. foetida) is pale, hoary and highly branched shrub belongs to family Chenopodiaceae. It is widely distributed in Bahrain, India, Afghanistan, Saudi Arabia, and North America [3]. In Pakistan, it grows in Punjab, Baluchistan, Sindh, Trans-Indus areas and desert of Cholistan [4, 5]. The plant material was extracted by maceration technique in our previous studies. The solvent was evaporated with the help of rotary vacuum evaporator to make it concentrate. Salsolide was new compound isolated and then characterized from the root of this plant. It showed antioxidant effects $[4,6]$.

\section{Materials and Methods}

Salsola baryosma Linn root was used as a plant material. The identification of this plant was performed at 
Cholistan Institute of Desert studies at The Islamia University of Bahawalpur with voucher specimen SB-110.

\section{Preparation of Herbal Extracts}

The shade dried pulverized plant root material was used to prepare extracts. The solvents, petroleum ether, chloroform and ethanol were used for successive extraction. The solvents were evaporated by passing through rotary vacuum evaporator to make the extract concentrated as described in Figure 1.

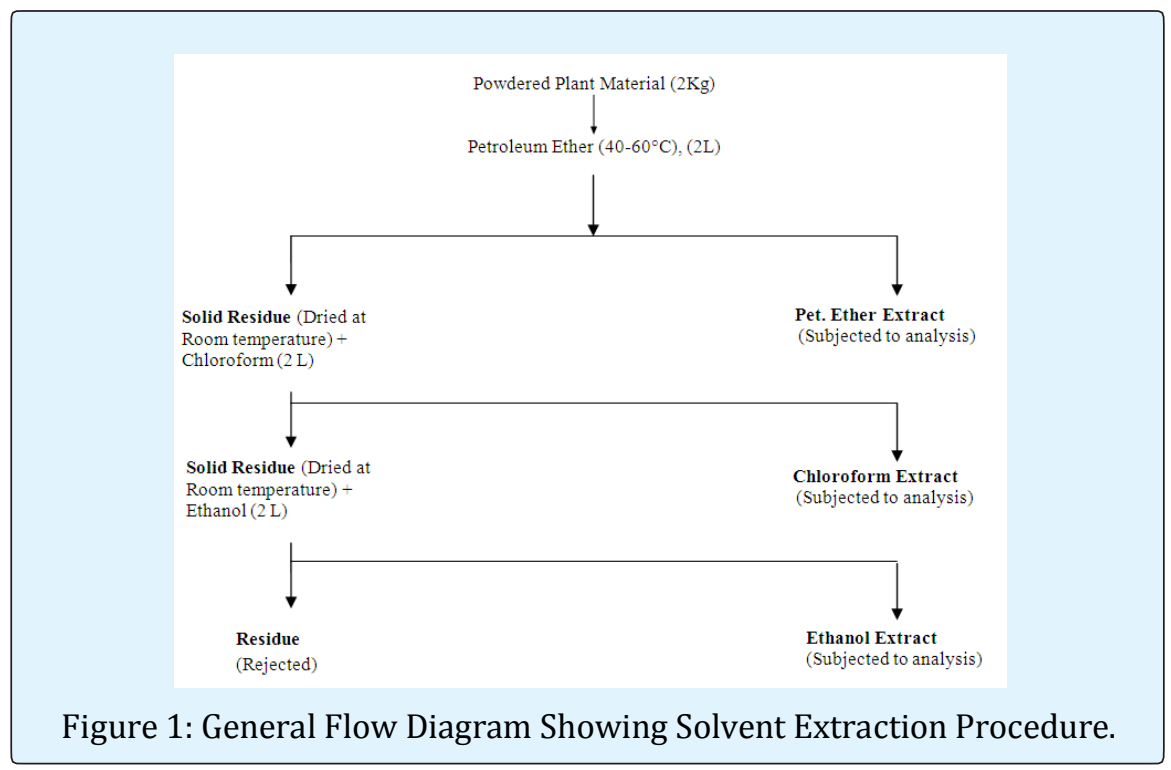

\section{Preparation of Base and Formulations}

23 factorial designs was applied for designing different formulations. The variables were extract, stearic acid and glycerin. The oil phase consisting of stearic acid $(11 \%$ to $13 \%)$, cetostearyl alcohol (2\%) and methyl paraben $(0.1 \%)$ were heated at $60 \mathrm{oC} \pm 1^{\circ} \mathrm{C}$ in water bath. The water phase consists of propyl paraben $(0.05 \%)$, potassium hydroxide (KOH) $(0.90 \%)$, glycerin $(8 \%$ to $10 \%)$, extract $(1 \%$ to $3 \%)$ and distilled water $(100 \%$ q.s). The water phase was heated at $50^{\circ} \mathrm{C} \pm 1^{\circ} \mathrm{C}$ and finally added in the oil phase. The water phase was added drop wise with continuous stirring with overhead stirrer. The stirring speed was gradually slowed down to get the homogeneous mixing until the cream cooled down to room temperature (Table 1).

\begin{tabular}{|c|c|c|c|c|c|c|c|c|}
\hline $\begin{array}{c}\text { Base/ } \\
\text { Formulation }\end{array}$ & $\begin{array}{c}\text { Stearic Acid } \\
\text { (\%) }\end{array}$ & $\begin{array}{c}\text { Cetostearyl } \\
\text { Alcohol }\end{array}$ & $\begin{array}{c}\text { Methyl } \\
\text { Paraben }\end{array}$ & $\begin{array}{c}\text { Propyl } \\
\text { Paraben }\end{array}$ & $\begin{array}{c}\text { Potassium } \\
\text { Hydroxide }\end{array}$ & Glycerin & Extract & $\begin{array}{c}\text { Distilled Water } \\
\text { (q.s 100) }\end{array}$ \\
\hline Base & 13 & 2 & 0.1 & 0.05 & 0.9 & 10 & --- & 100 \\
\hline P1*/C1*/E*1 & 11 & 2 & 0.1 & 0.05 & 0.9 & 10 & 3 & 100 \\
\hline P2/C2/E2 & 11 & 2 & 0.1 & 0.05 & 0.9 & 10 & 1 & 100 \\
\hline P3/C3//E3 & 11 & 2 & 0.1 & 0.05 & 0.9 & 8 & 3 & 100 \\
\hline P4/C4//E4 & 11 & 2 & 0.1 & 0.05 & 0.9 & 8 & 1 & 100 \\
\hline P5/C5/E5 & 13 & 2 & 0.1 & 0.05 & 0.9 & 10 & 3 & 100 \\
\hline P6/C6/E6 & 13 & 2 & 0.1 & 0.05 & 0.9 & 8 & 1 & 100 \\
\hline P7/C7/E7 & 13 & 2 & 0.1 & 0.05 & 0.9 & 8 & 3 & 100 \\
\hline P8/C8/E8 & 13 & 2 & 0.1 & 0.05 & 0.9 & 10 & 1 & 100 \\
\hline P9/C9/E9 & 12 & 2 & 0.1 & 0.05 & 0.9 & 9 & 2 & 100 \\
\hline
\end{tabular}

${ }^{*} \mathrm{P}=$ Petroleum Ether, $\mathrm{C}=$ Chloroform $\mathrm{E}=$ Ethanol

All ingredients in percentage

Table 1: Factorial Design for Formulation of Base, Petroleum Ether Extract cream and Ethanol-water Extract cream. 


\section{Open Access Journal of Pharmaceutical Research}

\section{Selection of Creams}

The formulations prepared from extracts were subjected to accelerated conditions and were kept at $8^{\circ} \mathrm{C}$, $25^{\circ} \mathrm{C}$ and $40^{\circ} \mathrm{C}$ for 7 days. Cracking was observed and the most stable formulations were reformulated and further characterized.

\section{Stability Studies}

The selected creams from each extract were reformulated along with the base without any extract. Stability was evaluated by keeping bases and formulations at $8^{\circ} \mathrm{C}, 25^{\circ} \mathrm{C}$ and $40^{\circ} \mathrm{C}$ for 28 days. Homogeneity of color, emolliency liquification and type of smear were evaluated $[7,8]$.

\section{Centrifugation Test}

Centrifugation test was performed for freshly prepared creams. The test was repeated after 12 hours, 24 hours, 36 hours, 48 hours, 72 hours, 7 days, 14 days, 21 days and 28 days of preparation. The test was performed at $25^{\circ} \mathrm{C}$ at $5000 \mathrm{rpm}$ for 10 minutes by placing $5 \mathrm{~g}$ of sample in disposable stoppered centrifugal tubes. After centrifugation, phase separation of the creams was checked [9].

\section{Patch Test}

On the dorsal surface of the left hand, marked an area (5sq.cm) and cream was applied on that area and evaluated for irritancy upto $24 \mathrm{hrs}$ and reported.

pH Determination: $\mathrm{pH}$ values of freshly prepared creams and creams which were stable kept at $8^{\circ} \mathrm{C}, 25^{\circ} \mathrm{C}$ and $40^{\circ} \mathrm{C}$ for 28days were determined with the help of digital $\mathrm{pH}$ meter.

\section{Antimicrobial Activity}

The antimicrobial activity of stable creams and extracts were checked by comparing with streptomycin against Escherichia coli, Stephlococcus aureus, Pasteurella multicoda and Basillus subtillus. Disc diffusion method was used to check the zone of inhibitions (ZOI). The sterilized nutrient agar was used as culture media. The extracts and creams were diluted with their relevant solvent and distilled water respectively.

\section{Results}

\section{Selection of Creams}

The most stable creams were selected after 7days study. It was observed that only petroleum ether extract cream (P6), chloroform extracts cream (C6) and ethanolic extract cream (E6) formulations remained stable. On the other hand due to the process of cracking all other formulations were rejected. Further evaluation of these stable formulations (P6, C6 \& E6) and its relevant bases (PB, CB \& EB) without extracts was carried out.

\section{Stability Study}

Stability studies were performed at $8^{\circ} \mathrm{C}, 25^{\circ} \mathrm{C}$ and $40^{\circ} \mathrm{C}$. The physical characteristics, emolliency, liquification and type of smear remain stable at all the temperatures for the whole time of study. The slight change in colors of the petroleum ether formulation (P6) and ethanol formulation (E6) were noted on the 21st day at $40^{\circ} \mathrm{C}$ but cream base remained stable. Also, slight change in color was noted both in $\mathrm{C} 6$ formulation and cream base $\mathrm{CB}$ at $250 \mathrm{C}$ and $40^{\circ} \mathrm{C}$ on the 21 st day. The spreadability of the base PB remained stable during the study period at all temperatures. The spreadability of P6 slightly changed on the 21 st day at $40^{\circ} \mathrm{C}$ while of that of cream C6 changed at 250C and 400C.

\section{Centrifugation Test}

The test was performed for all formulations and bases after 12hours, 24hours, 36hours, 48hours, 72hours, 7 days, 14 days, 21 days and 28days. There was no phase separation noted in any base or formulation.

\section{Patch Test}

On the dorsal surface of the left hand, marked an area (5 sq.cm) and cream was applied on that area, covered with surgical dressing and then evaluated for irritancy. Then the volunteers were asked to mark their irritancy score scoring from 0 to 4,4 with maximum irritancy (Table 2).

\begin{tabular}{|c|c|c|c|c|c|}
\hline Formulation & Score & & & & \\
\hline & 0 & 1 & 2 & 3 & 4 \\
\hline Base & 19 & 1 & 0 & 0 & 0 \\
\hline Formulation & 16 & 2 & 2 & 0 & 0 \\
\hline
\end{tabular}

Table 2: Irritancy Score $(\mathrm{n}=20)$.

pH Determination: $\mathrm{pH}$ value of the freshly prepared creams (P6, C6, E6) and bases (PB, CB \& EB) were determined. The samples kept at $8^{\circ} \mathrm{C}, 25^{\circ} \mathrm{C}$ and $40^{\circ} \mathrm{C}$ were determined for 28 days at definite time periods with the help of digital $\mathrm{pH}$-meter and have been presented in table 1 . 


\section{Open Access Journal of Pharmaceutical Research}

The $\mathrm{pH}$ values of all the bases (PB, CB and $\mathrm{EB}$ ) were in the range of 5.41 to 5.55 while the $\mathrm{pH}$ of the formulations P6, C6 and E6 was in the range of 5.31 to 5.74. The pH values of the formulations containing chloroform extract and ethanol extract (C6 and E6) were slightly higher than the bases without extracts. The $\mathrm{pH}$ values of the formulation containing petroleum ether extract (P6) were slightly lower than the $\mathrm{pH}$ of the base without petroleum ether extract. There was not any pattern of $\mathrm{pH}$ values throughout the whole 28 days of study. The $\mathrm{pH}$ was remained almost stable during the period of study and was found to be in the range of the $\mathrm{pH}$ of the skin (Table 3).

\begin{tabular}{|c|c|c|c|c|c|c|c|c|c|c|c|c|c|c|c|c|c|c|}
\hline \multirow{3}{*}{ Time } & \multicolumn{6}{|c|}{$8^{\circ} \mathrm{C}$} & \multicolumn{6}{|c|}{$25^{\circ} \mathrm{C}$} & \multicolumn{6}{|c|}{$40^{\circ} \mathrm{C}$} \\
\hline & \multicolumn{2}{|c|}{\begin{tabular}{|c|}
$\begin{array}{c}\text { Petroleum } \\
\text { ether }\end{array}$ \\
\end{tabular}} & \multicolumn{2}{|c|}{ Chloroform } & \multicolumn{2}{|c|}{ Ethanol } & \multicolumn{2}{|c|}{$\begin{array}{c}\text { Petroleum } \\
\text { ether }\end{array}$} & \multicolumn{2}{|c|}{ Chloroform } & \multicolumn{2}{|c|}{ Ethanol } & \multicolumn{2}{|c|}{$\begin{array}{c}\text { Petroleum } \\
\text { ether }\end{array}$} & \multicolumn{2}{|c|}{ Chloroform } & \multicolumn{2}{|c|}{ Ethanol } \\
\hline & PB & P6 & CB & C6 & EB & E6 & PB & P6 & CB & C6 & EB & E6 & PB & P6 & CB & C6 & EB & E6 \\
\hline $0 \mathrm{Hr}$ & 5.43 & 5.35 & 5.43 & 5.67 & 5.42 & 5.69 & 5.43 & 5.35 & 5.43 & 5.67 & 5.42 & 5.7 & 5.43 & 5.35 & 5.43 & 5.67 & 5.43 & 5.69 \\
\hline $12 \mathrm{Hr}$ & 43 & 36 & 5.41 & 66 & 5.41 & 5.7 & 5.43 & .37 & 5.42 & 67 & 5.41 & 5.7 & 5.42 & .36 & 5.43 & 5.66 & 5.41 & 7 \\
\hline $24 \mathrm{Hr}$ & 43 & 35 & 5.43 & 64 & 44 & 5.71 & 5.42 & .34 & 5.42 & 5.62 & 5.44 & 5.74 & 5.44 & .33 & 5.44 & 5.64 & 5.44 & 5.71 \\
\hline $36 \mathrm{Hr}$ & 5.41 & 33 & 5.41 & 69 & 43 & 5.69 & 5.46 & .35 & 5.46 & 64 & 5.43 & 5.71 & 5.46 & 7 & 5.47 & 5.63 & 5.43 & 5.69 \\
\hline $48 \mathrm{Hr}$ & 5.42 & 5.37 & 5.42 & 5.63 & 5.42 & 5.72 & 5.48 & 5.38 & 5.48 & 5.68 & 5.42 & 5.7 & 5.45 & 5.34 & 5.45 & 5.62 & 5.44 & 5.72 \\
\hline $72 \mathrm{Hr}$ & 5.47 & 5 & 5.47 & 64 & 5.55 & 5.71 & 5.43 & 5.36 & 5.43 & 5.66 & 5.55 & 5.60 & 5.47 & 7 & 5.47 & 5.66 & 5.55 & 5.71 \\
\hline 7 Days & 5.44 & 5.34 & 5.44 & 5.61 & 5.44 & 5.74 & 5.46 & 5.32 & 5.46 & 5.64 & 5.44 & 5.71 & 5.45 & 5.33 & 5.45 & 5.68 & 5.44 & 5.74 \\
\hline 14 Days & 5.42 & 5.36 & 5.42 & 5.66 & 5.45 & 5.72 & 5.45 & 5.36 & 5.45 & 5.63 & 5.47 & $5.6 \mathrm{C}$ & 5.47 & 5.34 & 5.46 & 5.64 & 5.45 & 5.72 \\
\hline 21 Days & 5.46 & 5.35 & 5.46 & 5.63 & 5.43 & 5.74 & 5.43 & 5.34 & 5.43 & 5.67 & 5.45 & 5.74 & 5.5 & 5.32 & 5.5 & 5.61 & 5.42 & 5.74 \\
\hline 28 Days & 5.44 & 5.31 & 5.44 & 5.68 & 5.42 & 5.73 & 5.46 & 5.31 & 5.46 & 5.66 & 5.42 & 5.73 & 5.47 & 5.38 & 5.47 & 5.6 & 5.42 & 5.73 \\
\hline
\end{tabular}

$\mathrm{PB}=$ base for Petroleum ether extract formulation, $\mathrm{P} 6=$ formulation of petroleum ether extract, $\mathrm{CB}=$ base for $\mathrm{Chloroform}$ extract formulation, $\mathrm{C} 6=$ formulation of chloroform extract, $\mathrm{EB}=$ base for ethanol extract formulation, $\mathrm{E} 6=$ formulation of ethanol extract

Table 3: pH values of Bases PB, CB, EB and Formulations P6, C6 \& E6 prepared from extracts of Petroleum ether, Chloroform, and Ethanol respectively kept at $8^{\circ} \mathrm{C}, 25^{\circ} \mathrm{C}$ and $40^{\circ} \mathrm{C}$.

\section{Antimicrobial Activity}

Antimicrobial activities of the creams and crude extracts were evaluated by disc diffusion method. Nutrient agar was used a culture media for the growth of the microorganisms. Dilution factor was $100 \mathrm{mg} / \mathrm{ml}$. Dilutions of the creams were also made with Distilled water with the same factor of dilution. Sample was applied $100 \mu \mathrm{l}$ on the disc. Streptomycin was considered as a standard. Antimicrobial activity was checked against Escherichia coli, Staphylococcus aureus, Phostonila multicoda and Basillus subtillus. Petri dishes were incubated at $25 \pm 2^{\circ} \mathrm{C}$ and zone of inhibitions (ZOI) were measured. The extract of petroleum ether showed less antimicrobial activity as compared to standard. But the ZOI of cream P6 is comparatively less. The zones of inhibition of petroleum ether extract against Escherichia coli, Staphylococcus aureus, Phostonila multicoda and Basillus subtillus were 15, 18, 30 and $21 \mathrm{~mm}$. The zones of inhibitions made by P6 were 5, 2, 1 and $6 \mathrm{~mm}$. The chloroform extract showed antimicrobial activity and the ZOI were 25, 22, 27 and $20 \mathrm{~mm}$. The ZOI made by chloroform formulation (C6) were 8, 3, 2 and $5 \mathrm{~mm}$. The ethanol extract made ZOI 32, 27, 32 and $20 \mathrm{~mm}$ and ethanol extract formulation (E6) were 10, 4, 2 and $7 \mathrm{~mm}$. The activity of ethanol extract was more than petroleum ether extract and chloroform extract against all microbes (Figure 2 and 3). 

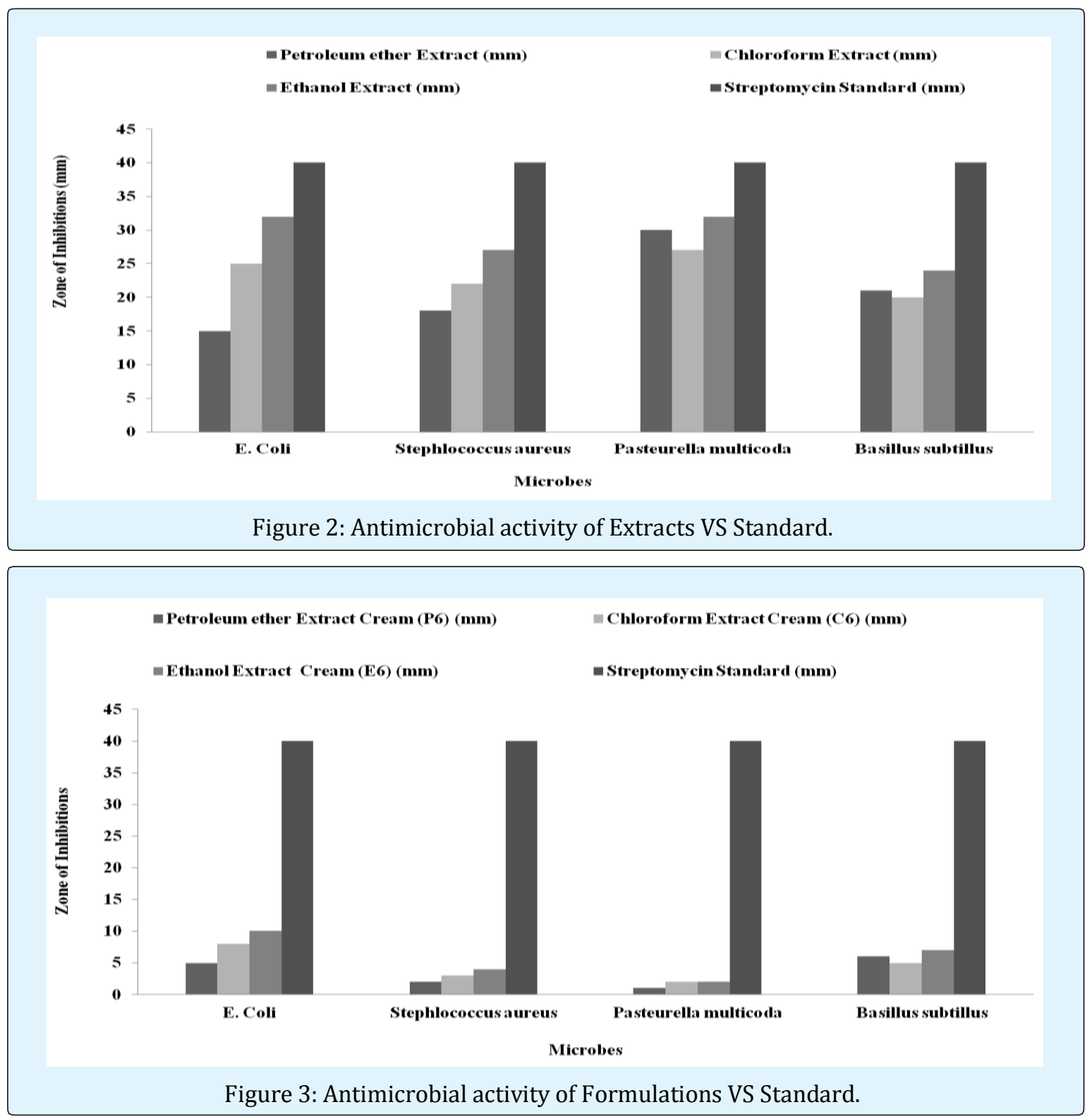

\section{Discussion}

The slight change in colors of the petroleum ether formulation (P6) and ethanol formulation (E6) and chloroform base were noted at $40^{\circ} \mathrm{C}$ but cream base remained stable. The spreadability of P6 slightly changed on the 21st day at $40^{\circ} \mathrm{C}$ while of that of cream C6 changed at $250 \mathrm{C}$ and $400 \mathrm{C}$. These changes may be due to oxidation of oil base component of the different bases and formulations.

It was noted that there was no change in cream consistency after subjecting to centrifugation so continuous stirring speed when applied, during preparation of bases and formulations have profound effect on the homogenous mixing and emulsion preparations that's why no phase separation was observed.

The formulations and bases showed no irritancy in case of chloroform and ethanol extract showing that the ingredients of formulations and base have not irritating and unpleasant effect on skin. But in case of Petroleum ether extract only four out of twenty volunteers gave the score of 1 and 2. Furthermore due to presence of glycerin and water emolliency was observed. 


\section{Open Access Journal of Pharmaceutical Research}

Two way ANOVA and analyzed the results of $\mathrm{pH}$ values of cream bases without extract (PB, CB \& EB) and cream formulations (P6, C6 \& E6). The level of significance was assumed to be $95 \%$. In case of petroleum ether extract formulation (P6), base (PB), chloroform formulation C6 and base $\mathrm{CB}$ the row factors are insignificant. The results are significant in case of column factors and are $<0.0001$. In case of ethanolic base (EB) and cream formulations (E6) showed both row and column factors significant.

Antimicrobial activities when analyzed it was observed that maximum zone of inhibition was seen in ethanol extract and cream. Two way ANOVA was applied for this analysis and the level of significance was measured. The level of significance was assumed to be $95 \%$. The results of row factors were insignificant and measured level of significance was $\mathrm{p}=0.4652$. The column factors showed significant results. The measured level of significance was $\mathrm{p}<0.0001$.

Salsola baryosma roots possess anti-microbial activity and has folk use for this in Cholistan desert, Pakistan. In this study extracts from roots of this plant were used for the preparation of cream which was then characterized by different methods. Finally the extracts and creams were evaluated for their effects on different microbes. It was observed that Salsola baryosma extracts and creams prepared by these extracts possess activity against E. coli, Stephlococcus aureus, Pasteurella multicoda and Basillus subtillus.

\section{Acknowledgement}

The authors are thankful to the Prof. Dr. Khwaja Zafar Ahmed, Dean, Faculty of Pharmaceutical Sciences, Govt. College University Faisalabad, Pakistan and Prof. Dr. Naveed Akhtar, Chairman, Department of Pharmacy, The Islamia University of Bahawalpur, Pakistan for the help they provided to conduct the study.

\section{References}

1. Bindurani R, Kumar K (2013) Evaluation of Antioxidant Activity of Hydro Distilled Extracts of Leaf, Heart Wood and Flower of Azadirachta Indica. Int J Pharm Sci Rev Res 20(2): 222-224.

2. Madupu PR (2011) Merits of using herbs in whole state (Ayurveda's concept) over isolated fractions. Int J Res Ayurveda pharm 2(1): 7-9.

3. Ahmed T, Hashim A (2000) Brine shrimp bioassay of ethanol extracts of Sesuvium verrucosum, Salsola baryosma and Zygophyllum quatarense Medicinal Plants from Bahrain. Phytother Res 14(1): 48-50.

4. Saeed A, Ashraf M, Iqbal MC, Jabbar A, Janbaz KH, et al. (2006) Pharmacological Screening of Salsola baryosma. J Chem Soc Pak 28(1): 82-83.

5. Nishi M, Joginder S, Sachendra B, Anil V (2007) Arbuscular Mycorrhizal Status of Medicinal Halophytes in Saline Areas of Indian Thar Desert. Int J Soil Sci 2(2): 119-127.

6. Saeed A, Ashraf M, Naheed R, Choudhary MI, Ghulam MM, et al. (2008) Salsolide, a new phydroxyphenylglycol derivative from Salsola baryosma. J Chem Soc Pak 30(1): 110-112.

7. Herbert A L, Martin MR, Gilbert SB. Pharmaceutical Emulsions, Pharmaceutical Dosage Forms: Disperse Systems, Vol. 1, New York and Basel, Marcel Dekker, 1988.

8. Derick R (2000) Fat crystals and emulsion stability, a review. Food Res Int 33(1): 3-14.

9. Nasrin A, Eskandar M, Abdulghani A (2007) Characterization of an Anti-Dermatophyte Cream from Zataria multiflora Boiss. Iran J Pharm Sci 3(2): 77-84. 